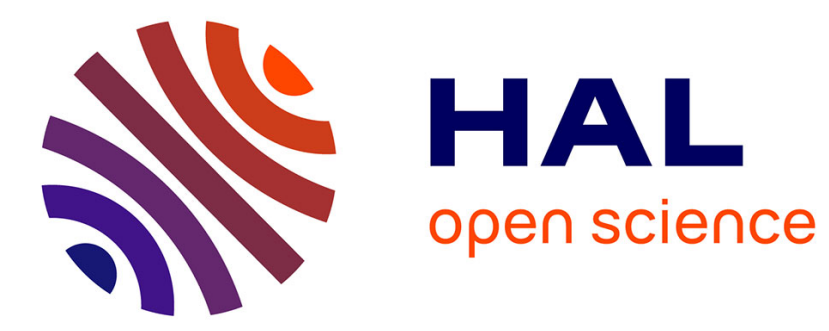

\title{
THE AMPLITUDE-PHASE DISTORTION AT THE PARAMETRIC SOUND WAVE CONJUGATION
}

\author{
A. Brysev, V. Strel'Tsov
}

\section{To cite this version:}

A. Brysev, V. Strel'Tsov. THE AMPLITUDE-PHASE DISTORTION AT THE PARAMETRIC SOUND WAVE CONJUGATION. Journal de Physique IV Proceedings, 1992, 02 (C1), pp.C1-903-

C1-906. 10.1051/jp4:19921197 . jpa-00251162

\section{HAL Id: jpa-00251162 https://hal.science/jpa-00251162}

Submitted on 1 Jan 1992

HAL is a multi-disciplinary open access archive for the deposit and dissemination of scientific research documents, whether they are published or not. The documents may come from teaching and research institutions in France or abroad, or from public or private research centers.
L'archive ouverte pluridisciplinaire HAL, est destinée au dépôt et à la diffusion de documents scientifiques de niveau recherche, publiés ou non, émanant des établissements d'enseignement et de recherche français ou étrangers, des laboratoires publics ou privés. 


\title{
THE AMPLITUDE-PHASE DISTORTION AT THE PARAMETRIC SOUND WAVE CONJUGATION
}

\author{
A.P. BRYSEV and V.N. STREL'TSOV \\ General Physics Institute of Russian Academy of Science, 38 Vavilov st., 117942 Moscow, USSR
}

\begin{abstract}
We investigate the ampiitude distortion of the contrary phase-conjugated wave, generated in the active plane-parallel parametric layer by the incident acoustic beam with hauss transverse profile. We treat both stable and unstable regimes.
\end{abstract}

One of the main problems for all mechanisms of the phase conjugation CPC in acoustics as well as in optics is the quality of the phase reproduction. In acoustics the most promising way of po realization lies in using of the interaction of the phonon oscillations with some other types of the collective excitations in

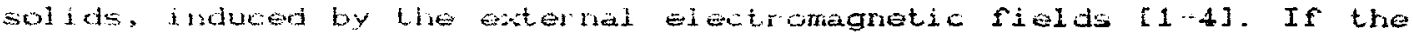
posatiliti or twophonon deway of the ruasi particle corresponding to the wetlin collective woikation sxists, the spatiaily homogeneous sound velust.y modulation at the exterral field frequency $\Omega$ arises. Thus, io zero quasi partite impulso the travolling of the sound wave with irequensy whre in subl media will be accompanied by the generation of the eontrary PC wave.

In this paper we irvestigate the expansion of tre lauss acoustic bon in the plenepirilifi iayer, the sound velocity in which is

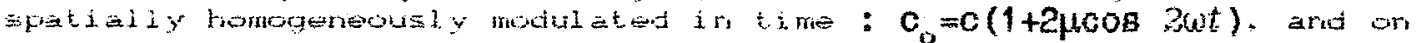
tris bases determine the implituds distortion of the output pc beam.

Let the incident quasi-plane acoustic impulse of the dur ation $T$

$$
U\left(z, \vec{r}_{1}, t\right)=0.5 U_{0}(t) \exp \left(-r_{1}^{2}-a^{2}\right) \exp [t(\omega t-k z)]+c . c .
$$

were $U$ is the displacement in acoustic waves, fall at the moment $t=0$ on the entrance surface $z=0$ of the plane-paraliel layer of the thickness 7 . If the modulation coerficient $\mu$ is small eriough, the full acoustic field in layer can be presented in the form:

$$
\mathrm{U}\left(\mathrm{z}, \overrightarrow{\mathrm{r}}_{1}, t\right)=0.5 \mathrm{U}^{+} \exp [i(\omega \mathrm{t}-\mathrm{kz})]+0.5 \cdot \mathrm{v}^{-} \exp [\tau(\omega \mathrm{t}+\mathrm{kz})]
$$

Then, for slowly varied along the $z$ ax and time $t c$ we assume, that the impulse duration $\tau$ si $w)$ amplitudes $U^{\ddagger}$ we posses the following coupled system :

$$
\begin{aligned}
& {\left[\frac{1}{2 i k} \Delta_{1}+\frac{\partial}{\partial z}+\frac{1}{2 i k} \cdot \frac{\partial^{2}}{\partial z^{2}}+\frac{1}{c} \cdot \frac{\partial}{\partial t}-\frac{1}{2 i k c^{2}} \cdot \frac{\partial^{2}}{\partial t^{2}}\right] v^{+*}=-\mu\left(t k+2 \frac{\partial}{\partial z}\right] v^{-}} \\
& {\left[\frac{1}{2 i k} \Delta_{1}+\frac{\partial}{\partial z}+\frac{1}{2 i k} \cdot \frac{\partial^{2}}{\partial z^{2}}-\frac{1}{c} \cdot \frac{\partial}{\partial t}-\frac{1}{2 i k c^{2}} \cdot \frac{\partial^{2}}{\partial t^{2}}\right] U^{-}=-\mu\left[i k+2 \frac{\partial}{\partial z}\right] U^{+*}}
\end{aligned}
$$

One can, easily ses, that in parabolic approximation $c \partial^{2}, \partial t^{2}=\partial^{2} / \partial z^{2}=0$, the output trarsverse distribution $U^{2}(z=0)$ of $t h e$ contrary wave ideally reproduces the input proflle of the incident. 
bean. Thus, the corrections arise, when we take irto account the above mentioned terms. Further, we shall look trough the situation. when the pumping intensity corresponds to stationary regime or small exceeds tha edgo of stability. In this case, as it is shown bellow, we tan neqlect the terms $\partial^{2} \partial t^{2}$. Further, we shall investigate separately two different $r \in g i$ mes.

i. Uristabie regine: $\mu \mathbf{k} l>\pi \%$.

Te solve (i) we perform the Luplaz-tramsform of $\mathrm{U}^{t}$ in time and Four ier-terisform al ong the trariverse spatial cowrdinates :

$$
\tilde{U}^{ \pm}\left(\vec{k}_{1}, p\right)=\int v^{t} e^{-p t_{e}}-i \vec{r}_{1} \vec{r}_{1} d t d \vec{r}_{1}
$$

Ther, for images, we get:

$$
\begin{aligned}
& {\left[\frac{1}{2 i k} \cdot \frac{\partial^{2}}{\partial z^{2}}+\frac{\partial}{\partial z}-\frac{k_{1}^{2}}{2 i k}+\frac{p}{c}\right] \mathrm{v}^{+*}=-\mu\left(i k+2 \frac{\partial}{\partial z}\right) \mathrm{u}^{-}} \\
& {\left[\frac{1}{2 i k} \cdot \frac{\partial^{2}}{\partial \mathrm{z}^{2}}+\frac{\partial}{\partial \mathrm{z}}-\frac{\mathbf{k}_{1}^{2}}{2 i \mathrm{k}}-\frac{\mathrm{p}}{\mathrm{c}}\right] \mathrm{v}^{-}=-\mu\left(i \mathrm{k}+2 \frac{\partial}{\partial \mathrm{z}}\right) \mathrm{v}^{+*}}
\end{aligned}
$$

We shall look for solution of the system with the boundary conditions:

$$
\tilde{U}^{+}(z=0)=\tilde{U}_{0}(p) \exp \left(-k_{1}^{2} a^{2}\right) ; \tilde{U}(z=l)=0 \text {; }
$$

the last equality means that the contrary wave at the back plare of the layer is absent. In all previous considerations we assumed that the level of the input signal is much higher, then the level ot the thermal noise in media, thus the acoustio radiation or spontariois sources car be reglected.

The characteristic equation, corresponding to fej for tirs

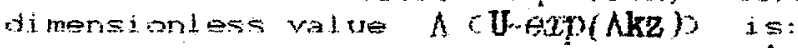

$\beta=\mathrm{k}_{\mathrm{l}}^{2} / 2 \mu \mathrm{k}^{2}$

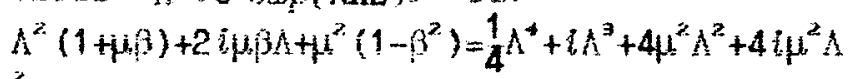

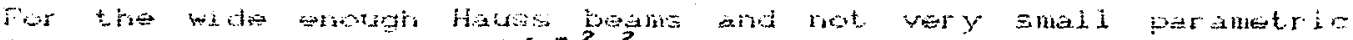

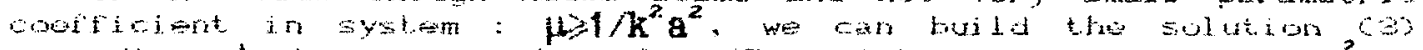

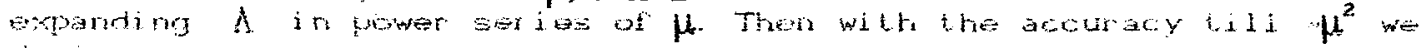
rer i ve:

$$
A_{1}=i \mu(1-\beta)+i \mu^{2}\left(3-2 \beta-\beta^{2}\right) \quad \text { in } \quad A_{2}=i \mu(1+\beta)+i \mu^{2}\left(3+2 \beta-\beta^{2}\right)
$$

Finaily, for the output Fourior ampiltucies of the contrary wave wa obtain

$$
\tilde{U}^{-}\left(\mathbf{k}_{1}, p, z=0\right)=\pi a^{2} \mu \tilde{U}_{0}^{*}(p) e^{-\frac{2}{4} k_{1}^{2} a^{2}}\left(1-e^{k\left(\Lambda_{2}-\Lambda_{1}\right) l}\right) \frac{\left(1+2 \Lambda_{1}\right)\left(1+2 \Lambda_{z}\right)}{\Delta}
$$

here $\quad \Delta=\mu-l \frac{p}{k G}-4 \mu \beta^{2}-\left[-\mu-i \frac{p}{\bar{k} c}+4 \mu \beta^{2}\right] e^{-2 i \mu k l(1-\mu \beta)}$

Further for definiteness we shall model the input time profile by the rectangular impulse with duration $t$ and amplitude $U_{0}$. Then $\tilde{\mathrm{U}}_{\mathrm{o}}^{*}(\mathrm{p})=\mathrm{U}_{\mathrm{o}}^{*}\left(1-\mathrm{e}^{-\mathrm{p} \tau}\right) / \mathrm{p}$

Tho integrand in $(4)$ is regular in complex plane $p$, except the simple poles, coineident with the roots $\quad h=0$. The reverse Laplas-transform for $\tilde{U}^{-}$for moments $t$ t tel/c can be carried out with the help of the residue theorem. The integral contour is ciosed in the left hali of $p$ plane. The transcendental equation $\Delta=0$ has the series of roots" with negative real parts $i s, b j$ and if, as it was assumed above. the pump small excous the edge of stability, the single root with positive real part. Thus, fill acoustic field is superposition or time attenuted modes and ore exporentially growing component, corresponding to that root. For the long enough time interval the 
attenuated modes will make the negligible contribution to the field, ther eby only the amplified mode should be taken into consideration.

Near the critical length $l$ : $\mu k l=\varepsilon+\pi, 2, \varepsilon * 1$, the root $\Delta=0$ we are interested in may be found by the expansion $p=p_{0}+\Delta p$. were $p_{0}$ is the root, corrosponding to $\mathbf{k}_{1}=0$. In its turn we can derive $\mathbf{p}_{0}$ by expanding $\Delta\left(\mathbf{k}_{1}=0\right)$ in a power row on a small deviation $\varepsilon$. After that, the corroction $\Delta p$, connected with smail transverse terms $\beta$, can be obtained by linearizing $\Delta(p)=\Delta\left(p_{0}\right)+\Delta^{\prime}\left(p_{v}\right) \Delta p=0$.

Finally, for output Fourier transform amplitude we have:

$$
\begin{aligned}
& \tilde{\mathrm{U}}^{-}\left(\overrightarrow{\mathrm{k}}_{1}, \mathrm{p}, z=0\right)=-i \pi \mu \mathrm{a}^{2} \mathrm{v}_{0}^{*} e^{-\frac{1}{4} \mathrm{k}_{\perp}^{2} \mathrm{a}^{2}}\left[1-\left(2-i \frac{\pi}{4}\right) \mathrm{k}_{1}^{2} / \mathrm{k}^{2}\right] \text { * } \\
& \times e^{\mu k c\left(\varepsilon-\frac{\pi}{4} k_{1}^{2} / k^{2}\right) t} \cdot \frac{1-e^{\mu k c\left(\varepsilon-\frac{\pi}{4} k_{1}^{2} / k^{2}\right) \tau}}{\mu\left(\varepsilon-\frac{\pi}{4} k_{1}^{2} / k^{2}\right)}
\end{aligned}
$$

It is seen. that gain of the transyerse Fourier-comporent declines as $\mathbf{k}_{1}$ increases. In reality the input impulse amplification on the spatial interval aqualed to the impulse length is small: ekct《1. Ther, expanding the corresponding exponent in (S) in row, after the reversset Fourier-transform we get:

$$
U^{-}(R, t, z=0)=-U_{0}^{*} \mu \mathbf{k c \tau} e^{\mu c \varepsilon t} e^{-R_{1}^{2} / \tilde{a}^{2}}\left[1+\frac{2 l \pi-8}{k^{2} a^{2}}\left[1-\frac{R^{2}}{\tilde{e}^{2}}\right]\left[\frac{a}{\tilde{a}}\right]^{2}\right]
$$

here $\quad \ddot{\mathrm{a}}^{2}=\mathrm{a}^{2}\left\{1+\pi \frac{\mu \mathrm{kCt}}{\mathrm{ka}}\right\}$.

As it follows from (6), the PC wave preserves the Hauss profile of the incident beam. The characteristic radius $\mathbf{a}$ monotonously increases in time - time dependant defocusing takes place. The speed of a rising depends both or diffraction parameter 1,ka and modulation coefficiert 11. The level of output signal is proportional to the input impulso duration.

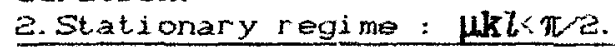

The coupled travelling of incident and contrary waves in stationary regime is deseribed by the systems $(1), 62)$. were the terms with time derivations are to be omitted. The characteristic equation (3) and its roots, as one can verify, remain valid in our case and, since we assume the same boundary conditions, the output fourier amplitude of the contrary wave is presented:

$$
\tilde{U}^{-}(\mathrm{z}=0)=\frac{i}{4 \pi^{2}}\left(1+3 \mu^{2}\right) \int \hat{U}_{0} \operatorname{tg}\left[\mu \mathrm{k} l\left(1-\mathrm{k}_{1}^{2} / 2 \mathrm{k}^{2}\right)\right] e^{i \overrightarrow{\mathrm{k}}_{1} \overrightarrow{\mathbf{r}}_{1}} \mathrm{dr}_{1}
$$

wer $\tilde{U}_{0}=U_{0} \exp \left(-0.25 k_{1}^{2} a^{2}\right)-F o u r i$ er-image of input signal.

We see, that near the edge of stability cukl $\rightarrow \pi / 23$ the tg-multiplier sharply depends on transverse variable $k_{1}$. In 1 ts turn, it 1 eads to sharp spectrum distortion of the output amplitude.

The spectrum of input signal cut of the output amplitude spectrum. Ther, within characteristic integration interval $k_{1} \leqslant a^{-i}$ we car expand $\operatorname{tg}\left[\mu k l k_{1}^{2} / 2 k^{2}\right)$ in row of small parameter $k_{1}^{2} / k^{2}$ and hold the main term. It is convenient to present the inverse fourier-transform in the form: 


$$
\begin{aligned}
& U^{-}(z=0)=\imath U_{o}^{*} a^{2} \pi\left(1+3 \mu^{2}\right) b^{2} t g(\mu k l)\left[k_{0}\left(b r_{1}\right) \int_{0}^{r} r_{1}^{i} e^{-r_{1}^{2} a^{2}} J_{0}\left(k_{1} r_{1}^{*}\right) d r_{i}^{*}+\right. \\
& \left.+d_{0}\left(b r_{1}\right) \int_{r}^{\infty} r_{i} e^{-r_{i}^{2} / a^{2}} \mathrm{~K}_{0}\left(b r_{i}\right) d r_{i}\right]
\end{aligned}
$$

were $b^{2}=2 k^{2} \mu k l \operatorname{tg}(\mu k l)$; Jo, $\mathrm{K}^{*}$ - Bessel functions. As it follows from (7). for the length $l$ far from oritical $\mathrm{k}^{2} \mathrm{a}^{2}$ ilk $l t g(\mu k l)$ the quality of amplitude reproduction is high:

$$
U^{-}(z=0)=i\left(1+3 \mu^{2}\right) v_{0}^{*} e^{-r_{1}^{2}-a^{2}}\left[1-2 \mu k l\left(r_{1}-a\right)^{2} \operatorname{tg}(\mu k l)-k^{2} a^{2}\right] t g(\mu k l)
$$

At the contrary relation between diffraction parameter and gain in the system for the most interesting transverse coordinate interval $r_{1} \leqslant a$ it's easy to obtain the following approximation, expanding Jo, Ko in power row of parameter bri:

$$
\begin{gathered}
U^{-}\left(z=0, r_{1} \leqslant q\right)=i U_{0}^{*} \frac{\left(1+3 \mu^{2}\right) k^{2} a^{2}}{\mu k l}\left\{K_{0}(\varepsilon q)\left(1-e^{-q^{2}}\right)-\right. \\
\left.-I_{0}(\varepsilon q)\left[\left(\ln \frac{\varepsilon q}{2}+c\right) e^{-q^{2}}-\frac{1}{2} E 1\left(-q^{2}\right)\right]\right\}
\end{gathered}
$$

here $E=a b \ll 1 ; q=r_{1} / \mathbf{a}$ - dimensionlass transverse coordinate; C-Eyler constant.

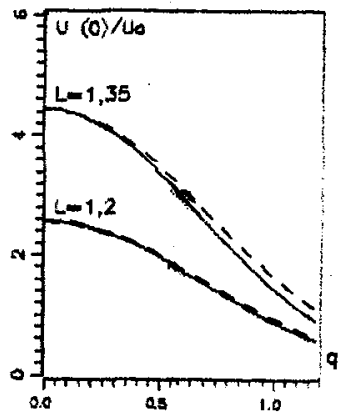

Figure.

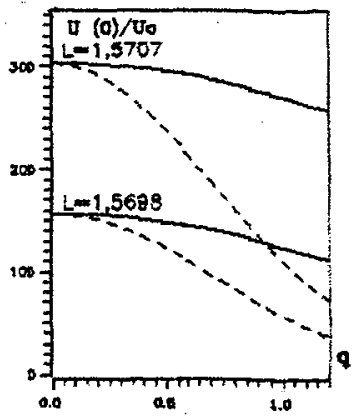

In Fig. we show the $U^{-}(z=0, q)$ curves for various dimensionless $\mathrm{L}=1 \mathrm{k} i$ at the typical diffraction parameter value (ka) ${ }^{2}=100$. For comparison the Hauss profiles of the incident beam with the corresponding amplitude transformations are presented - dashed lines. One can see, that the output signal amplitude increases as $I$ increases, but simultaneously the amplitude distortion rises. Thus, the stationary PC at the high gain in the system vanishes.

In conclusion we note that, though the results were obtained for the model distribution of the incident beam, they still have more general significance. The inevitable sharp changes in output spatial spectrum at the arbitrary spectrum of the input signal near the edige of stability will al ways causes the phase and amplitude distortion of the cortrary beam.

REFERENCES.

[1]. Strel'tsov V.N., Kvantovaya Electron. CMoscows $13,2144,(19363$.

[2]. Bryser A.P., 'Strel'tsov V.N. Sov. Phys. Acoust., 3265), 408, (1986).

[3]. Bryser A.P., Strel'tsor V.N. Soviet Physics-Lebedey Institute Reports th 5, 26, (1987).

[4]. Bryser A.P., Strel'tsov V.N. Proc. of 1st France Acoust. Congr Coll. de Phys., suppl. He, v. 51 , c2-85, (1990).

[5]. Kroll N. M. J. Appl. Phys. 38, 34, C1065).

[6]. Bobroff D. L. , Haus H. A., J.App1. Phys. 38, 390, 61967 ). 